\title{
Equity Market Price Interactions Between China and the Other Markets Within the Chinese States Equity Markets
}

\author{
Gary Gang Tian* \\ University of Wollongong, Australia
}

This study examines the cointegrating and long-term causal relationships of equity market prices in equity markets of Chinese states namely, Shanghai, Shenzhen, Hong Kong, Taiwan and Singapore. I cover the period between October 5, 1992 and March 20, 2006, taking into account both the Asian financial crisis and the opening-up of China's equity markets in recent years. First, I analysis the cointegration by utilizing Johansen's (1988) cointegration tests. I find that a long-term equilibrium relationship measured by cointegration has been established among Shanghai, Shenzhen, Hong Kong and Taiwanese markets and, to a lesser degree, between these markets and the Singapore market since 1998. Secondly, this study examines causality by exploring the bootstrapped Toda-Yamamoto non-causality tests. I find that there is strong evidence of a bi-directional causality between Shanghai and Shenzhen markets after 1998. Furthermore, I also find that there are more causal linkages between the Chinese states equity markets: two mainland Chinese markets, Hong Kong, Taiwan, and Singapore became more dependent on each other. The robustness of the above findings is confirmed by the use of a bootstrap test employed to test the validity of my results.

Keywords: international financial markets; causality testing in VaRs with bootstrapping, cointegration

\section{Introduction}

Economic integration between four ethnically homogeneous economies, China, Hong Kong, Taiwan and Singapore, emerged in the late 1970s as China gradually opened her markets to international trade and direct

\footnotetext{
* The author is grateful to the two anonymous referees' comments, suggestions by the editor-in-chief of the Multinational Finance Journal, Professor Theodossiou, and also comments made by Professor Raja Junankar and Professor Satya Paul. The research assistance by Mingyuan Guo is acknowledged. The authors remain responsible for all errors.
}

(Multinational Finance Journal, 2008, vol. 12, no. 1/2, pp. 105-126)

Quarterly publication of the Multinational Finance Society, a nonprofit corporation.

(C) Global Business Publications. All rights reserved.

DOI: $10.17578 / 12-1 / 2-5$ 
foreign investment and implemented market-orientated economic reforms. These four economies complement each another, with China providing land and labor for manufacturing at low costs, and Taiwan, Singapore and Hong Kong providing capital and technical expertise. Economic ties have been strengthened within this region by improved relationships between these economies, coupled with the return of Hong Kong to the PRC on July 1, 1997.

In addition to strengthened real economic links, interaction among financial markets within the region started to develop as early as the early 1990s and has accelerated in recent years. This financial interaction took place in two opposing ways: both local investment in overseas markets and foreign equity investment in local markets. First, Chinese firms are allowed to enter international markets to raise capital as well as awareness of their brands, particularly in the Hong Kong and Singapore markets because they are more developed and most importantly less regulated than the Taiwan market. A year after issuing A-shares to its domestic investors in 1992, China issued its first $\mathrm{H}$-share Tisngdao Beer listed in the Stock Exchange of Hong Kong (SEHK) on July 1993. Besides the H-share, there are 'cross-border' listings taking place among the Hong Kong registered mainland Chinese companies ('Red chips'). The number of these H-shares and Red-chips has been growing rapidly, stabilizing at around 38 and 28 respectively in recent years. Some of these shares are the top trading shares in the SEHK, and have taken a dominant role in the SEHK. For example, China Mobile accounts for $16 \%$ of the total market capitalization of the Hang Seng Index at the time of this being written. Following the SEHK, the Stock Exchange of Singapore (SGX) became another important venue for Chinese firms to be listed. These Chinese listed companies are called "dragon chips" in Singapore and have been actively traded since 2001. The number of companies from the Chinese mainland listed on the SGX has increased significantly since 2003. As a result, a total of 103 Chinese companies are listed on the SGX, accounting for more than 14 percent of all companies listed on the market (Shanghai Daily, May 25 2006). Most recently in May 2006, China implemented the QDII (Qualified domestic Institutional Investor) policy by allowing its domestic investors to invest foreign equities.

Secondly, in addition to allowing its local firms to be listed on international markets, after issuing A-shares to its domestic investors China started issuing B-shares to foreign investors as early as 1992. However, the operation of the B-share markets were not very successful 
at attracting foreign equity investment, because these B-shares were thinly traded and the total capitalization of B-share markets was less than about five percent of their counterpart A-share markets. ${ }^{1}$ In a bold step, China introduced the QFII (Qualified Foreign Institutional Investor) program as a provision for foreign capital to access its' A-share market, including bond markets, on 5 November 2002. Due to the growing importance of the Chinese equity markets and the acceleration of the real economic integration within the region, the mainland A-share markets have attracted increasing interest from international investors for their long-term portfolio diversification as well as short-term speculative purposes. ${ }^{2}$ It is expected that the recent opening of A-share markets (with the introduction of the QFII regulation) and the deregulation of local firms investment and listing in overseas markets, will allow for the progressive interaction between Chinese and global markets.

Overall, the segmentation/integration between the mainland markets and other regional markets, as well as international markets deserves more attention and vigorous empirical investigation. There are two hypotheses to be investigated. First, that the mainland markets have become more integrated with the other regional markets and even with main international markets including the U.S. and the Japanese markets, since these four regional economies have strengthened their economic relationships with each other and the Chinese government's recent gradual relaxation of restrictions upon foreign and domestic investment. Secondly, that the mainland markets have become influenced by the Hong Kong/Singapore and other international markets, as research has found that the Hong Kong/Singapore markets lead the emerging Asian markets, while the U.S. market influences a majority of the rest markets

1. The total capitalization of B-shares is much smaller than that of A-shares. At the end of 2003, there were only 111 B-shares with a total of capitalization about RMB 166 billion (\$U.S. 20 billion), which was about only $4 \%$ of combined total market capitalization of two exchanges at the same time. Besides, the market for B shares is very thin. Furthermore, in February 2001, the restriction to B-shares for domestic investors was relaxed. It became permissible for domestic investors with foreign currency holdings for trading B-shares. The difference between A and B shares diminished thereafter. Therefore, this study doesn't cover B-shares due to their negligibility and insignificance. Instead, I use the A share indices as more closely capturing the dominant trends in these mainland stock markets.

2. China's stock exchanges started as relatively new players in the region just recent years and have expanded rapidly in terms of capitalization, turnover, and the number of firms listed since their establishment; with the result being China's stock market becoming the second largest in Asia, behind only Japan (Groenewold, Tang and Wu [2004]). 
in the world.

A number of researchers have applied cointegration tests and Granger no-causality test to address the issue of equity market integration between mainland China and other markets. ${ }^{3}$ Both Huang and Yang (2000) and Groenewold, Tang and Wu (2004) found evidence of cointegration between the two mainland indices for the period before the Asian crisis, while Groenewold, et al. (2004) found that cointegration disappears after the crisis and during the post-crisis up to November 2001. There is no evidence to suggest in the existing studies that there is any cointegration existing between the mainland markets and any other markets.

As far as the causality tests are concerned, Chan and Lo (2000), Huang, Yang and $\mathrm{Hu}$ (2000) and Groenewold et al. (2004) find a strong but relatively isolated lead-lag relationship between the two mainland markets. Groenewold et al. (2004) also find that, after the Asian crisis, there is evidence to suggest that Hong Kong has a weak predicative power from returns in the mainland in addition to its strong influence on Taiwan. By adding the Singapore market to their dataset, Hatemi-J and Roca (2004) found that before the Asian crisis, the causality ran from Singapore to the markets of Taiwan and Hong Kong. However, after the Asian crisis, Singapore and Taiwan became more influential as they affected the other markets including the Hong Kong and Chinese markets. Although there are some differences among the research, all the above-mentioned studies conclude that Chinese stock markets are still relatively isolated even from their neighboring markets.

This study examines the cointegration and the long-term causal linkages within the Chinese states and between the region and major international markets. The paper departs from previous work in several ways, and contributes to the following areas:

The existing studies have mainly utilized statistics and econometric methods which are based on asymptotic methods. This can lead to biased inferences in the presence of non-normality and ARCH effects, mainly in the daily data, which is well known to characterize financial variables (Hatemi-J and Roca [2004]) particularly for newly established emerging markets such as the Shanghai and Shenzhen markets. First, as far as causality tests are concerned, this study addresses this gap in the literature through the use of the Toda-Yamamoto (1995) causality test which I

3. These publications include Kim and Shin (2000), Laurence, Cai and Qian (1997), Lo and Chan (2000), Poon (2000) and Sjoo and Zhang (2000). 
bootstrap. The robustness of the results of the Granger causality tests is confirmed by the use of a bootstrap test employed to test the validity of the results. Secondly, this paper uses weekly logarithm price data for cointegration tests, which largely improves the non-normality found in the daily data and mostly passes the post-estimation diagnostic tests.

This study extents its investigation into the period up to $30 \mathrm{March}$ 2006, which covers the period when the Chinese government sped up its relaxation on capital restriction of both foreign equity investment and domestic listing internationally since the end of 2002. It is expected that there was a cointegrating and causal relationship being established between the Chinese stock markets and the regional stock markets and possibly international stock markets during this period.

This study also differs from other studies by using both Shanghai and Shenzhen A share market indices rather than combining these two indices into one portfolio index. I believe two separate indices reveal much more information than the one artificially combined in regards to cointegration and causality relations. Furthermore, this study extends the previous study on greater China stock markets to Chinese states equity markets by including the Singapore market due to its strong link to the other four markets in the region. Thus, the present study provides a significant contribution to the existing literature.

The remainder of this paper is organized as follows: Section II discusses the characteristics of the data and presents the results of some diagnostic tests; Section III sets out model specification and methodology issues; Section IV demonstrates empirical results, and finally in Section V, conclusions and a discussion of the economic implications are presented.

\section{Market Characteristics and Data Properties}

We collected daily data of five stock markets in the Chinese states as well as Japan and the U.S. These are Shanghai's A share index (DataStream code: CHSASHR), or ShA, Shenzhen's A share Sub index (SHZASUB, SzA), the Hang Seng Index of Hong Kong (HNGKNGI, HKSI), Taiwan's value-weighted index (TAIWGHT, TWII), Singapore's new Straits Time (SNGPORI, SGP), Nikkei 225 stock average (JAPDOWA, JAP) and Standard and Poor's 500 index (S\&PCOMP, SP). All of these indices are based on closing prices. Data is obtained from DataStream International and covers the period between 5 October 1992 and 20 
March 2006, the starting date being the earliest date for which the information of the Shenzhen market was available.

Table 1 provides some descriptive statistics of our sample. To analyze the extent of market integration over time, they are reported for the two subsamples: pre-financial crisis between 5 October 1992 and 30 June 1997 and post-financial crisis between 1 July 1998 and 20 March 2006. I also report the results for the post-financial crisis between 1 July 1998 and 1 September 2001, which were used in the previously published articles, in order to compare with them. The crisis period between July 1997 and June 1998 was omitted in order to isolate the effects of the Asian financial crisis. Trading over that period only reflected noise and overreaction trading.

Although the returns for all markets including both the Chinese markets were higher after the crisis than they were before, volatility between mainland and non-mainland markets showed different trends. While skewness, excess kurtosis and normality statistics in non-mainland markets remained at a similar level after the financial crisis, all these indicators for the relatively isolated mainland Chinese markets substantially declined during the post crisis period. Greater kurtosis values for the Chinese markets during the pre crisis period indicate a relatively short history of the two markets in which a great majority of the price changes occurred around that period. These results are consistent with the finding by Bekaert and Harvey (1995) that return volatility in emerging markets is greater than that of developed markets, and that volatility is time varied.

The correlation matrix for the pre and post-crisis sub-periods are reported in table 2 . The top panel of the table displays the correlations between the pre-crisis index returns, while the lower panel displays the corresponding correlations for the post-crisis period. As expected, the correlations among various stock index returns are mostly positive. A comparison of the correlation coefficients for all market pairs across the pre and post crisis period reveals an increase in correlations over the post crisis period. However, there are substantial increases in the correlation coefficients between mainland markets and other regional markets over the same period of time. The correlation coefficient between these two Chinese markets themselves was much higher than that of the rest of the markets for all the periods. This correlation coefficient increased from 0.69 during the pre-crisis period to 0.94 over the post crisis period. 


\section{Statistical Methodology}

\section{A. Multivariate Cointegration Analysis}

The procedure based on Johansen (1988) is used for testing cointegration. Johansen's (1988) multivariate cointegration model is based on the error correction representation given by:

$$
\Delta X_{t}=\sum_{i=1}^{k-1} \Gamma_{i} \Delta X_{t-k}+\mu+\Phi D_{t}+\varepsilon_{t}
$$

where $X_{t}$ is a column vector of $k$ variables, $\mu$ is a $(k \times 1)$ vector of constant terms, $\Gamma$ and $\Pi$ represent coefficient matrices, $\Delta$ is a difference operator, $k$ denotes the lag length, and $\varepsilon_{t} \sim \mathrm{N}(0, \Sigma)$. Johansen's methodology requires the estimation of the VAR equation (1) and residuals, which are then used to compute two likelihood ratio $(L R)$ test statistics that can be used in the determination of the unique cointegrating vectors of $X_{t}$.

The next step is to specify the model, which involves determining the optimal lag length of the levels of own and other variables in the model. Two lag selection methods (Akaike Information Criterion (AIC) and Schwarz Criterion $(S C)$ ) are used based on the recommendation found in Giles and Mirza (1999). When the difference between the resulting lag orders is large, and because there are sufficient observations in this case, I favor the AIC lag selection (Giles and Mirza [1999]). I then check to see whether the chosen lag orders from each stock index pass the diagnostic tests. However, the chosen lag number is not reported in table 3 in order to save space.

\section{B. Causal Inference in Toda-Yamamoto Level Vars Including Integrated and Cointegrated Processes of Arbitrary Orders}

The procedure for Granger no-causality tests developed by Toda and Yamamoto (1995) utilizes a modified WALD test for restrictions on the parameters of a VAR $(k)$, or MWALD procedure (where $k$ is the lag length in the system). The advantage of this procedure is that it does not require precise knowledge of the integration properties of the system. In addition, a standard vector autoregression in the levels of the variables can be fitted into the model. It can be applied even when there 


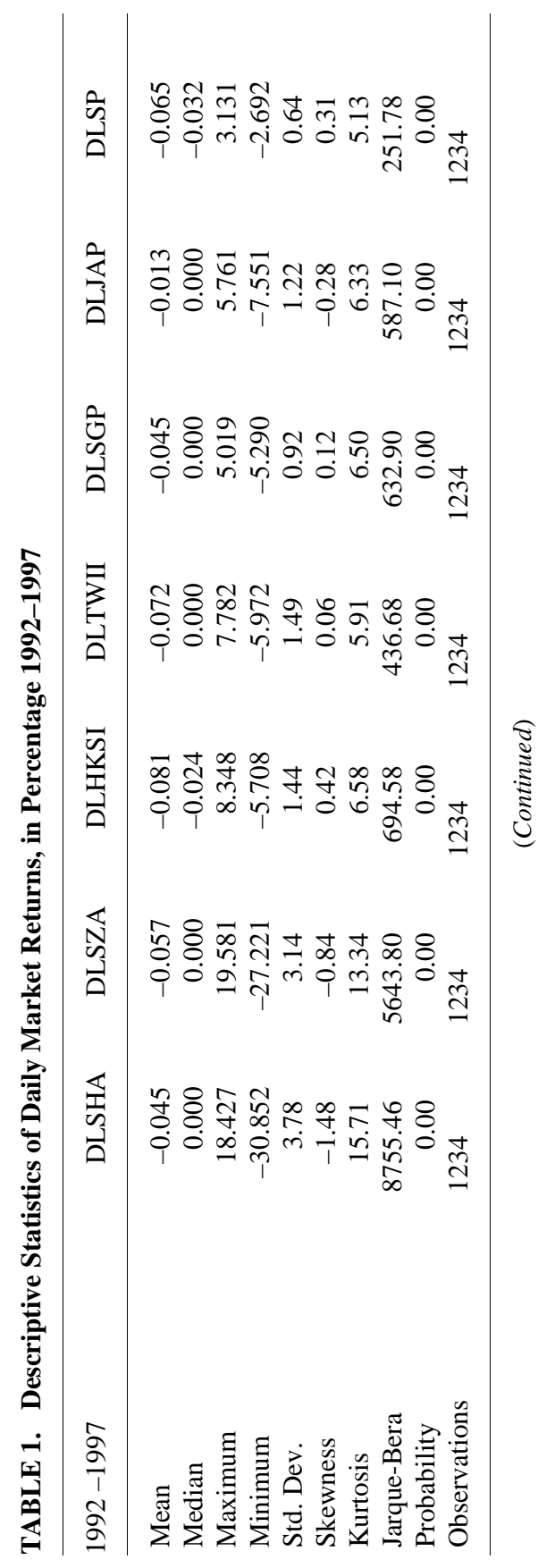




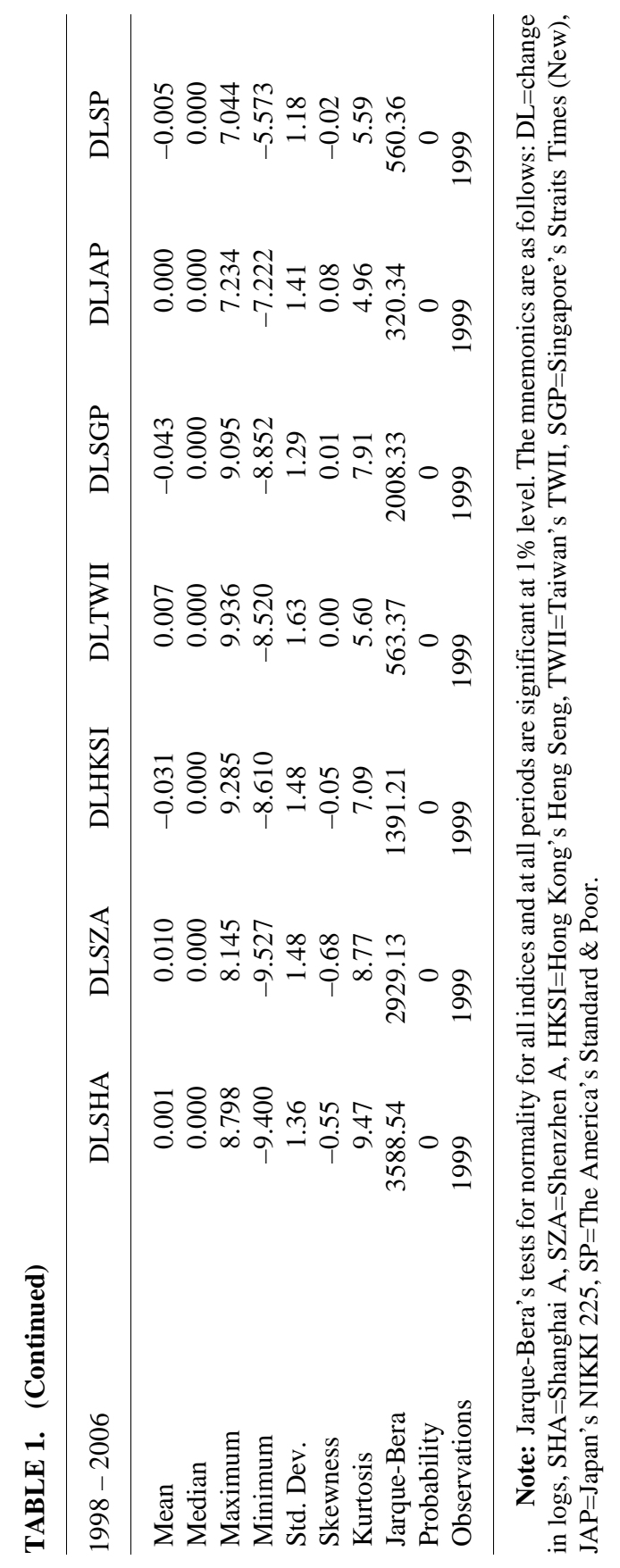




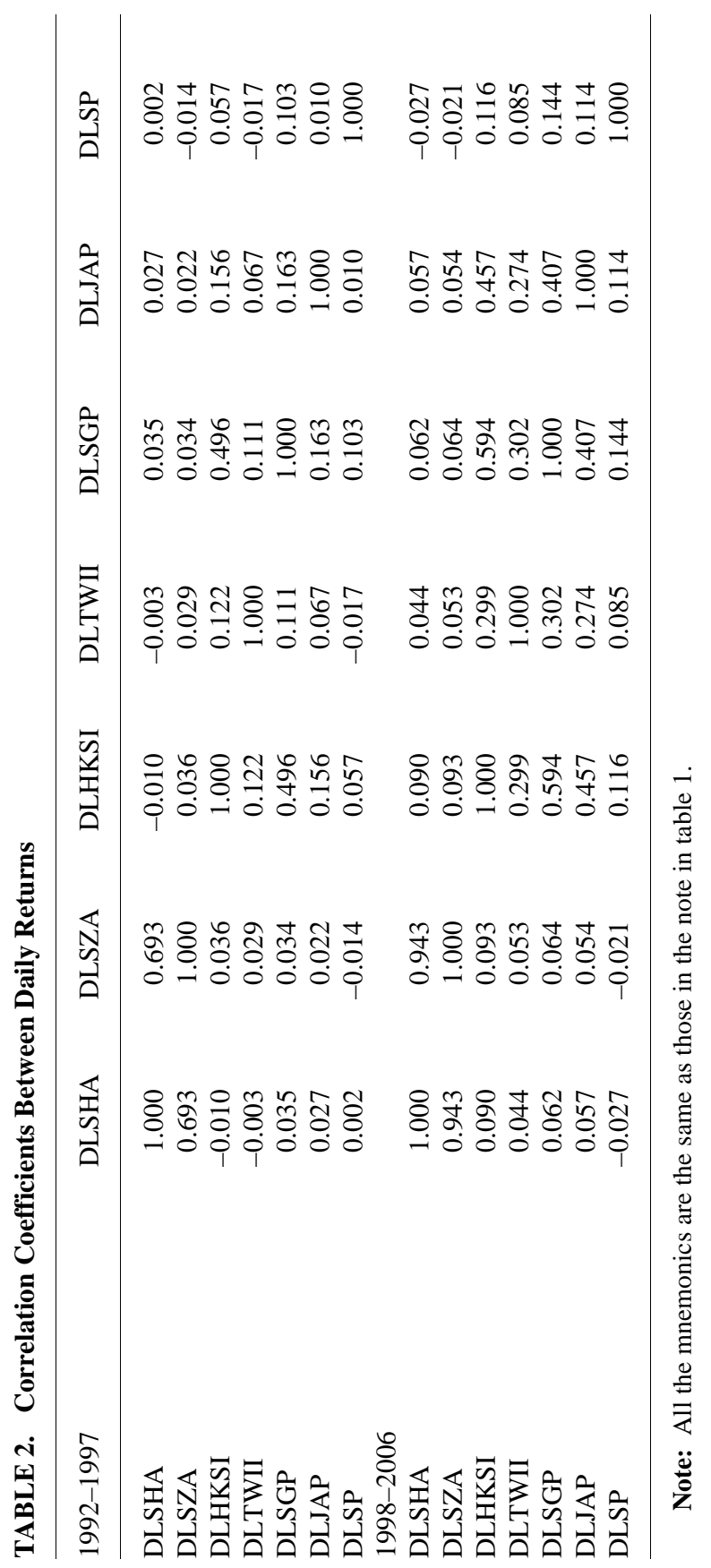


is no integration and/or stability and rank conditions are not satisfied 'so long as the order of integration of the process does not exceed the true lag length of the model' (Toda and Yamamoto [1995]). This technique allows us to examine the interrelated nature of stock prices in different securities markets by using a multivariate VAR When there is no cointegration other than a causal relationship existing among the stock markets concerned.

However, the MWald test statistic is asymptotically $\chi^{2}$ distributed, and conditional on the assumption that the error terms are normally distributed, with the number of degrees of freedom equal to the number of restrictions being tested. Hacker and Hatemi-J (2002) show through Monte Carlo experiments that the MWald test statistic over rejects the null hypothesis, especially if the data generation process for the error terms is characterized by non-normality and autoregressive conditional heteroscedasticity (ARCH). Under such circumstances, a bootstrap method is used to improve on the inference based on tests for causality. The bootstrap technique is based on resampling the date set to estimate the distribution of a test statistic. Using this distribution can decrease bias in an inference by providing more precise critical values. By conducing the bootstrap simulation 1000 times and then producing the $M W A L D$ test statistic each time, I can generate the empirical distribution for the $M W A L D$ test statistic.

\section{Results and Analysis}

\section{A. Unit Root Tests}

Prior to testing for cointegration and causal relationship between the markets, it is necessary to test for stationarity and establish the order of integration present in each data series. Table 3 presents unit root test statistics for all data series. Results are reported for the augmented Dickey and Fuller test, the Generalized least square $(D F-G L S)$ Dickey-Fuller tests, and Pillips-Perron $(P P)$ test. The $D F-G L S$ test is similar to an augmented Dickey-Fuller $t$ test, but it substantially increased statistical power when there is an unknown mean or trend present (Elliott, Rothenberg and Stock [1996]). All these tests are consistent with the hypothesis of a unit root type of non-stationarity in the data. 


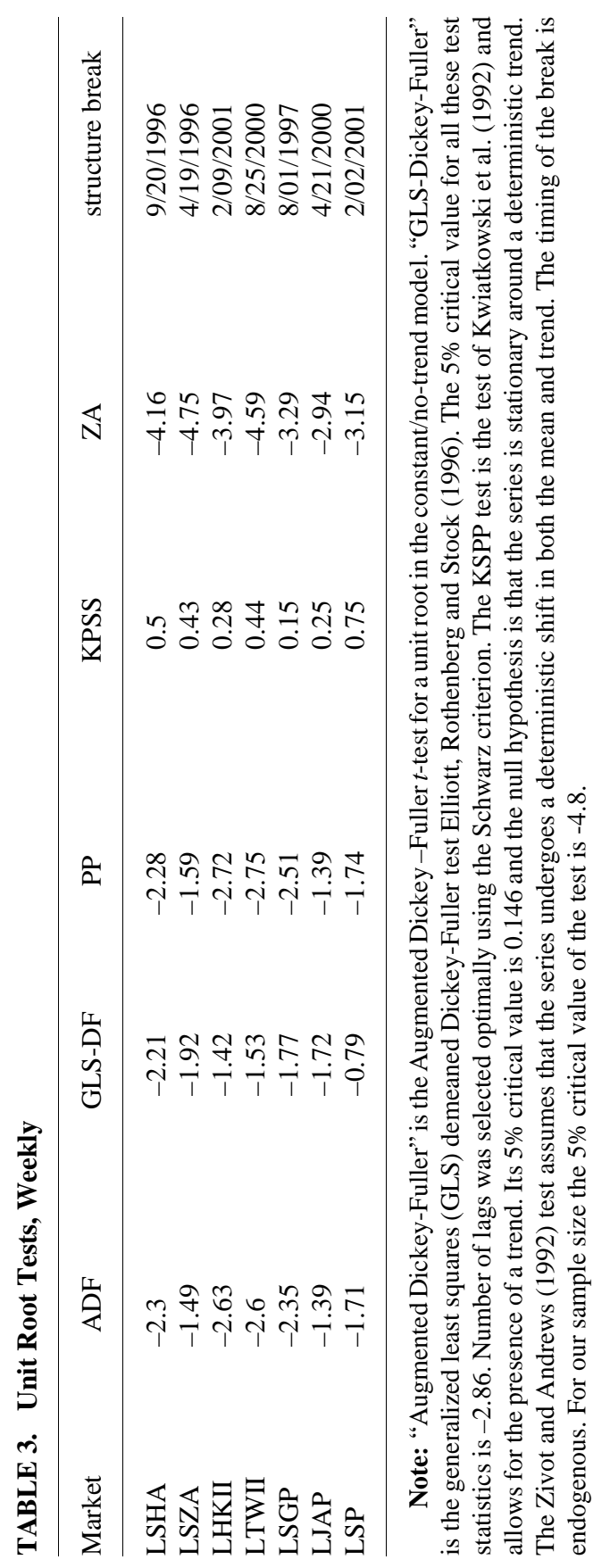


To supplement the analysis, two alternative unit root tests, including the KPSS test by Kwiatkowski et al. (1992) and the Zivot and Andrews (1992) test, have been computed. These alternative statistics also exhibit nonstationary log stock indices at the significance level of 5\%. All these traditional $A D F$-type tests and tests for unit roots with structure breaks were carried out on both the leveled and differenced time series. Thus, one can conclude that all the log stock index series are $I(1)$. The reports of the results of tests on the differenced forms will be available upon request.

Following the literature (Toda and Yamamoto [1995]; Rambaldi and Doran [1996]; Zapata and Rambaldi [1997]), a VAR $(k+d \max )$ model is set up in order to examine whether the lead-lag relationships between all these markets differ over the various periods. Given that the orders of integration for all these time series of log prices are $I$ (1), i.e., the order of dmax is chosen to be one, the next step is to augment the VAR by the maximum order of integration in the series. Here the lag selection is three, but a $(k+1=3)$ order VAR is then estimated for non-causality by using MWald test statistics.

The following VAR $(k+d \max )$ model is used in investigating lead-lag relationships among these markets,

$$
\left[\begin{array}{l}
l s h a_{t} \\
l s z a_{t} \\
l h k s i_{t} \\
l t w i i_{t} \\
l s g p_{t} \\
l j a p_{t} \\
l s p_{t}
\end{array}\right]=A_{0}+\sum_{i=1}^{k} A_{i}\left[\begin{array}{c}
l s h a_{t-i} \\
l s z a_{t-i} \\
l h k s i_{t-i} \\
l t w i i_{t-1} \\
l s g p_{t-i} \\
l j p a_{t-i} \\
l s p_{t-i-1}
\end{array}\right]+\sum_{j=k+1}^{d \max } A_{j}\left[\begin{array}{c}
l s h a_{t-j} \\
l s z a_{t-j} \\
l h k s i_{t-j} \\
l t w i i_{t-j} \\
l s g p_{t-j} \\
l j a p_{t-j} \\
l s p_{t-j-1}
\end{array}\right]+\left[\begin{array}{l}
\varepsilon_{l s h a_{t}} \\
\varepsilon_{l s z a_{t}} \\
\varepsilon_{l h k s i_{t}} \\
\varepsilon_{l t w i i_{t}} \\
\varepsilon_{l s g p_{t}} \\
\varepsilon_{l j a p_{t}} \\
\varepsilon_{l s p_{t}}
\end{array}\right]
$$

where $A_{0}$ and $\mathrm{A}_{1}-\mathrm{A}_{d \max }$ are $(7 \times 1)$ and $(7 \times 4)$ matrices of coefficients respectively and vector $(\mathcal{E})$ is white noise. 


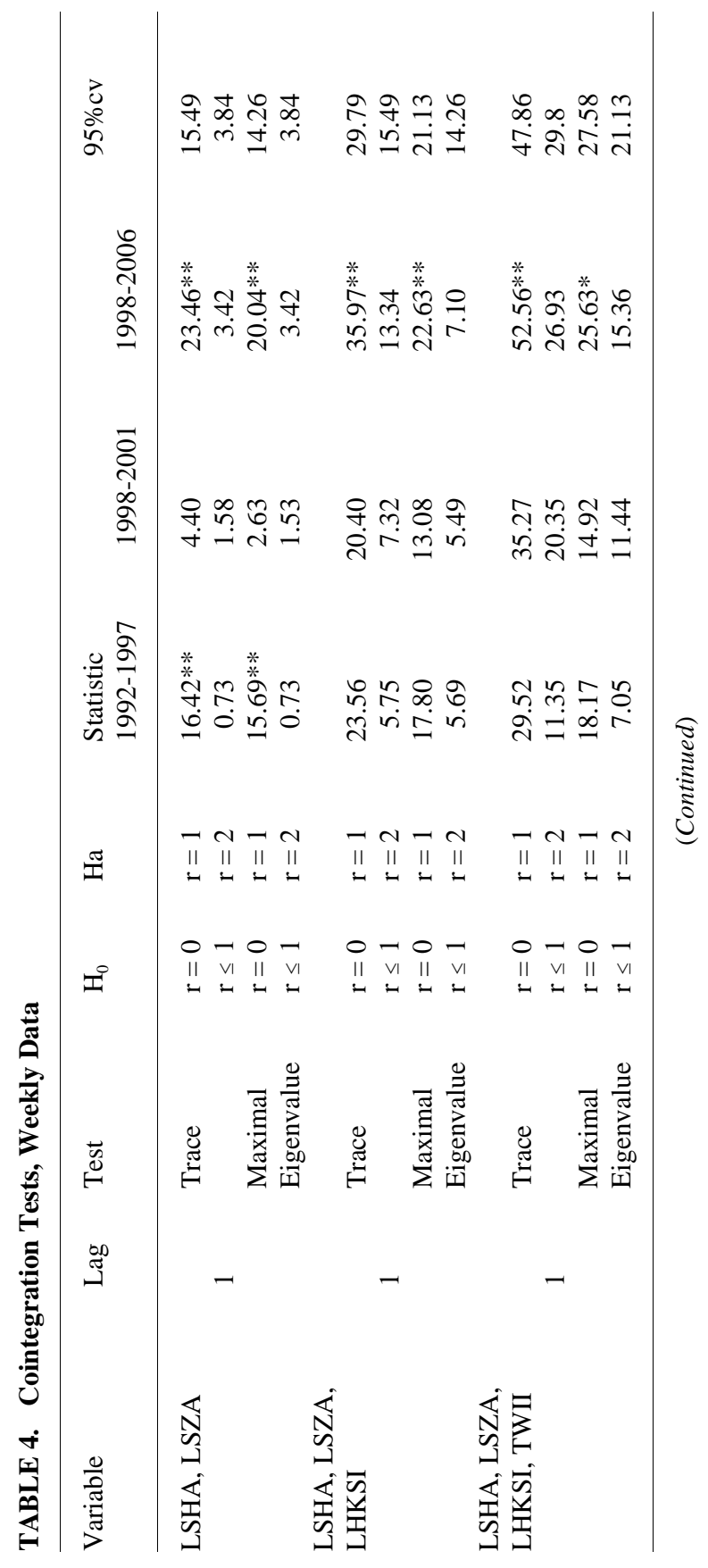




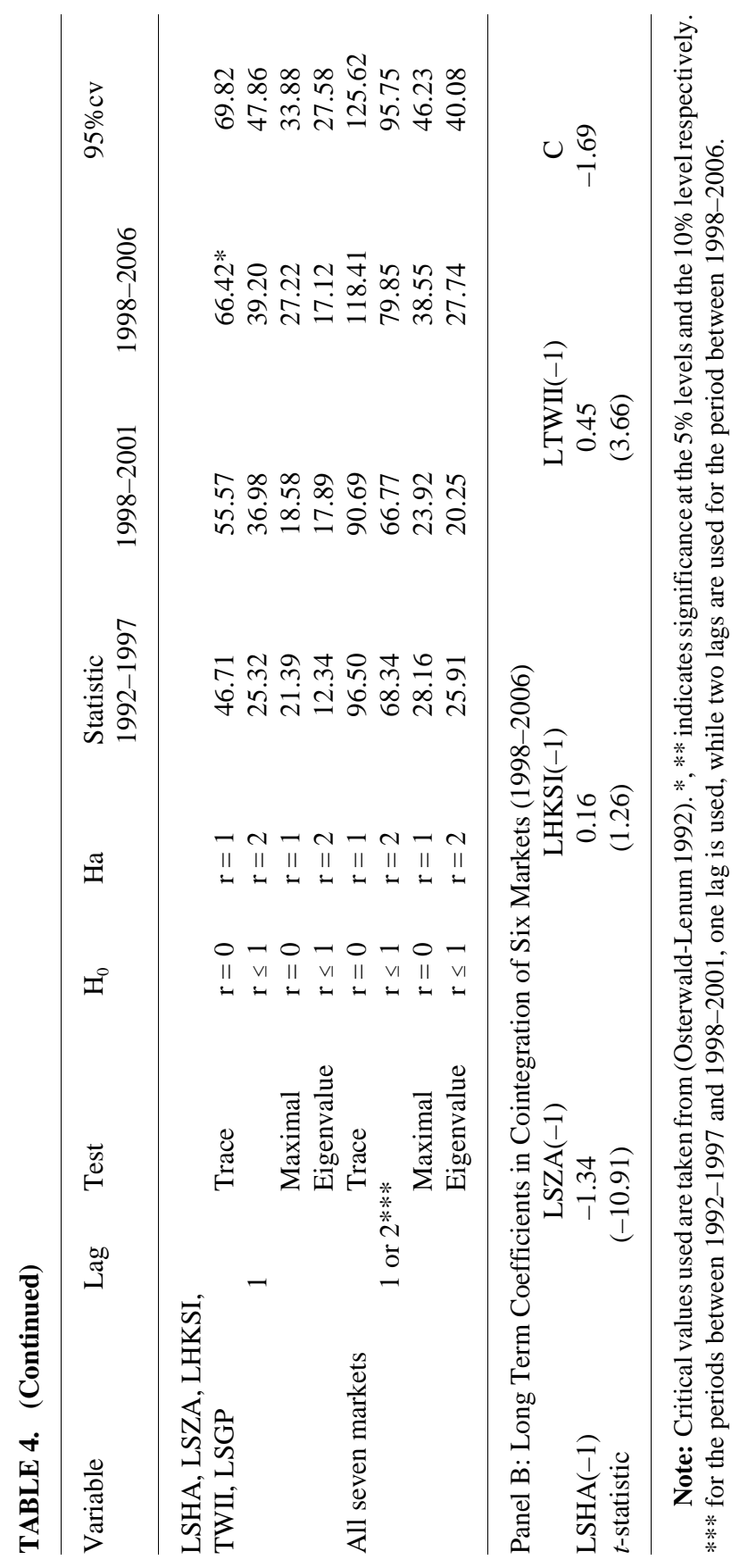




\section{B. Cointegration Tests}

The results of the cointegration tests are reported in table 4, which include results for the two subsamples. Given the unimportance of trends in stationary tests, the Johansen statistics with a model were computed without a trend. I began with a test involving just the two Mainland Chinese stock prices in order to examine the relationship between these two markets in isolation. I next combined the two Chinese indices with the price of Hong Kong Heng Seng index and further added an additional index each time until the full set of seven market indices was reached. The results of all these seven cointegration tests are reported in table 4 . I found that there is evidence of only a cointegration relationship between these two mainland Chinese markets at a 5\% level of significance for the pre crisis period while this cointegration relationship disappeared during the post crisis period up to the late 2001. These results are consistent with the results from both Huang et al. (2000) and Groenewold et al. (2004).

However, once the post crisis period was extended to early 2006, evidence of cointegration between these two mainland Chinese markets can be found at a 5\% level of significance. This contradicts the results which Groenewold et al. (2004) achieved. Furthermore, I also find evidence to suggest that cointegration exists not only among the Chinese and Hong Kong markets, but also among all markets within the region including Taiwan and Singapore. The latter is significant at a 5\% level according to the trace test only. ${ }^{4}$ I found no evidence to suggest that cointegration exists among all seven markets, once the U.S. and Japan is included. A plausible explanation for the different results I obtained should be that the dataset used was four years longer, which is inclusive of the period in which China has experienced a further opening of its financial markets to foreign investors as well as relaxing the controlling of domestic firms listing in overseas markets in addition to the different statistical methodologies applied in this research.

\section{Causality Tests Based on Toda-Yamamoto Level Var}

The results of the Granger non-causality and bootstrap tests are presented in table 5 . The results between the two procedures are similar.

4. It is pointed out that the trace test shows more robust results than the maximal Eigenvalue test. The author appreciates one of the referees comments. 
There are long term rather than short term causality flows, since in this case all variables appear in levels. Consistent with a majority of studies, our results also indicate that two markets (the U.S. and J.P.) seem to be weakly exogenous. Therefore, I do not report these two markets as dependent variables in the results. The dominance of the U.S. market is clearly present, with its influence on equity markets in Taiwan, Hong Kong and Singapore. In addition, during the period before the Asian crisis, Singapore Granger-caused Taiwan while it was influenced by Hong Kong. Given that the U.S. had influence on both Singapore and Hong Kong, it is therefore also possible that Singapore's impact on Taiwan and Hong Kong's impact on Singapore could actually have been a U.S. effect that was being transmitted. I found no evidence that Hong Kong led Taiwan as did in Huang et al. (2000). This result is consistent with Hatemi-J and Roca (2004) who argued that Hong Kong was in the process of adjustment as it reverted back to China in 1997. The Shenzhen market uni-directionally Granger-causes the Shanghai market, while these two Mainland markets have no causal links with any of other markets. The independence of mainland markets was attributed to the fact that China was a relatively new market having just reopened in 1992.

After the Asian crisis, there were more causal linkages among the Chinese states equity markets. Singapore, Taiwan and Hong Kong became more dependent on each other. There were two-way Granger causality relations between Singapore and Hong Kong, while the Singapore market was also influenced by Taiwan. On the other hand, there were two-way Granger causality relations established between the two Mainland markets. What is more important is that the two Mainland markets became influenced by all the other Chinese states' equity markets, except that both Japan and U.S. markets had no influence on either mainland market. This result reinforced our findings in the previous session that during the post-Asian crisis cointegration had been established among Chinese states equity markets, which is mainly attributed to the fact the China has experienced a further opening of its financial markets to foreign investors as well as relaxing the controlling of domestic firms listing in overseas markets particularly in its neighboring markets. 


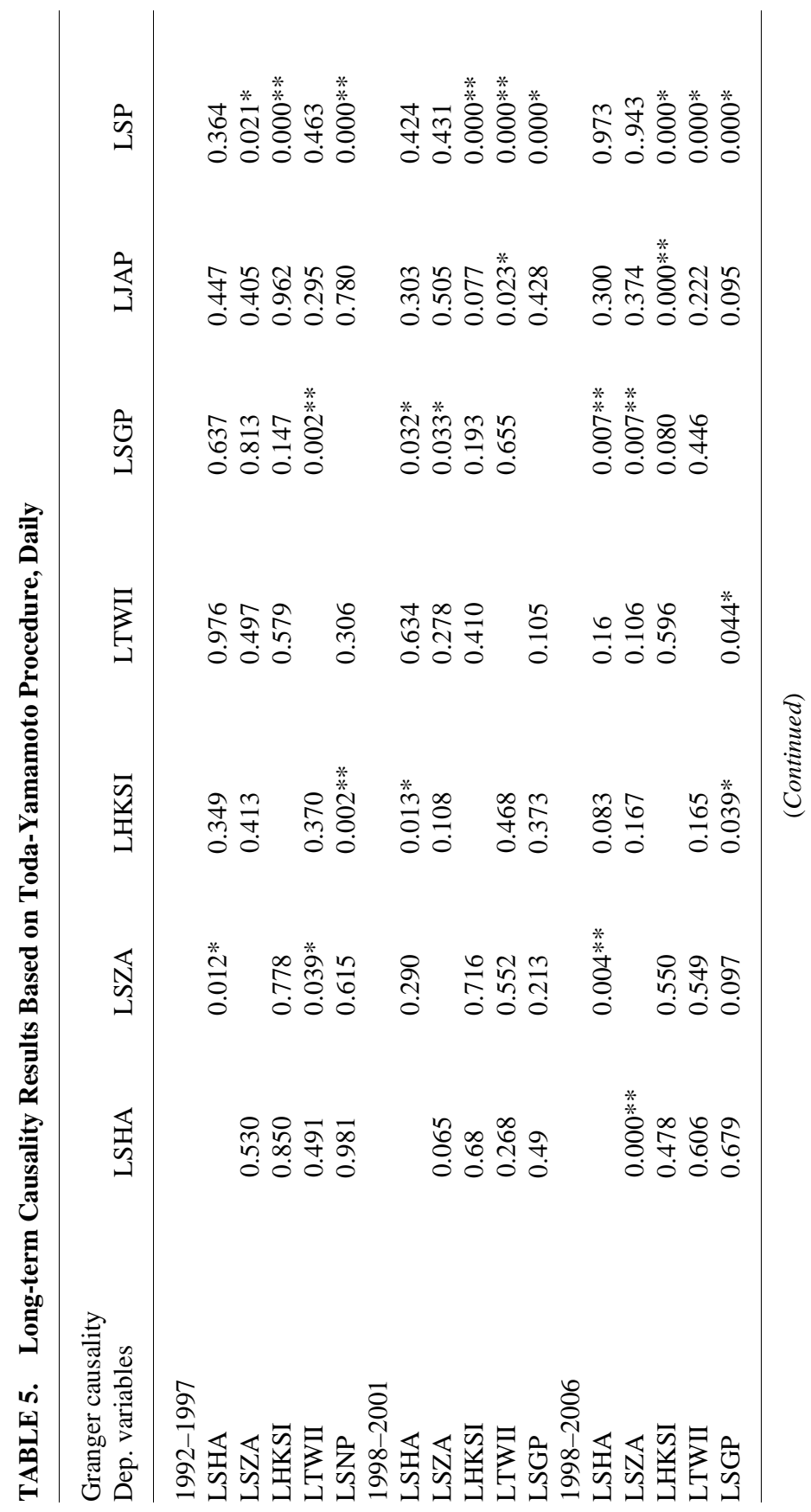




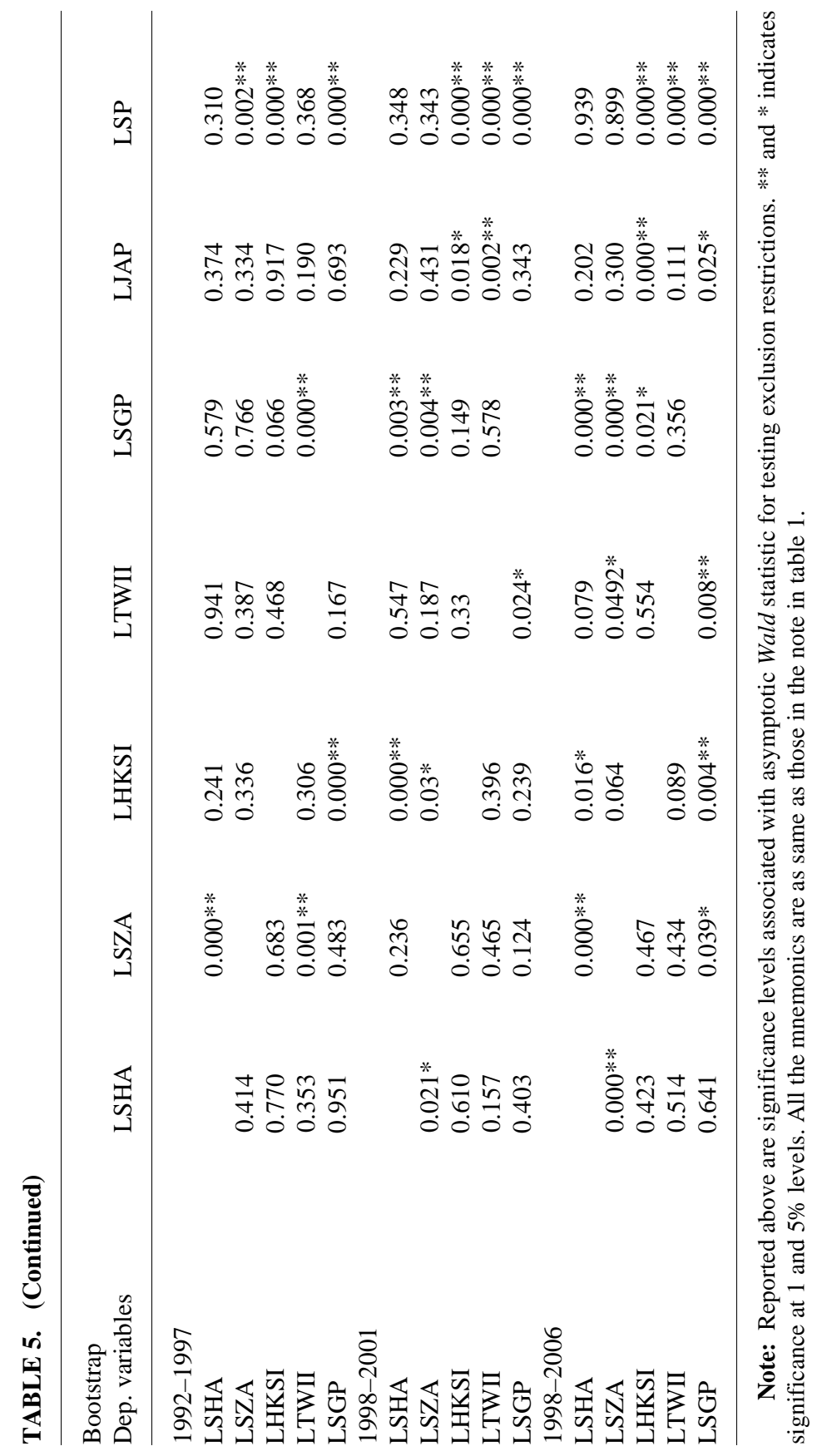




\section{Conclusion and Economic Implications}

\section{A. Conclusion}

Based on Johansen's multivariate cointegration tests, I found that the cointegration relationship between the SHSE and SZSE remained after 1997. I also found that there is evidence to suggest that a new cointegration emerged among the five Chinese states equity markets during the period between 1998 and 2006. During the pre-crisis period, only the Shenzhen market uni-directionally Granger-causes the Shanghai market, while China had no causal links with any of the other markets. This situation has changed dramatically since the Asian crisis. I found evidence of a long-term feed-back (bidirectional) causal relationship existing between the two mainland markets during the post crisis period. What is more important is that the mainland markets became influenced by all the other Chinese states' equity markets during the same period. Both the cointegration and causality tests indicated that the Chinese mainland markets became more regionally integrated, which can mainly be attributed to the fact that there are increasingly huge amount of portfolio funds move either from overseas into China domestic markets or from domestic firms into overseas markets thanks to the new policies implemented in recent years.

\section{B. Economic implications}

Our findings have implications for both policymakers and investors. The results suggest that broader economic integration developments and liberalization in Chinese states' economies after the Asian financial crisis have given rise to an integrated capital market within this region. Meanwhile, China's WTO accession and further opening of its domestic equity markets for foreign investors and overseas markets for domestic firms after 2001 has resulted in the emergence of a cointegration relationship between the markets in the region and other major international markets, though the latter is based on fairly weak evidence. I documented that Chinese markets experienced rapid growth in terms of capitalization and the number of firms listed along with a substantial decline in their volatility indicators for price returns (standard deviation, skewness and excess kurtosis) after a decade's development, indicating the markets are maturing. Besides the underlying economic integration and liberalization, the Chinese markets' maturation is the cause as well 
as the effect of their integration with other markets.

The implication of the established financial integration within the region is far beyond the initial Chinese government's motivation for raising capital for its state-owned enterprises. As a major step after China's WTO accession, the Chinese QFII program introduced in 2001 not only further opened China's securities markets, but also gave foreign investors opportunities to take positions on those markets and buy stakes in Chinese companies, thus sharing in China's phenomenal growth. This new QFII regulation has been a bold development in China's financial markets and has allowed for progressive interaction between the Chinese and global markets as suggested by some evidence of a cointegration relationship found between Chinese markets and major international financial markets. Meanwhile, the QFII's supply of long-term and stable capital and their targeting of companies with strong fundamentals, fiscal transparency and good governance, could contribute to the further development of the mainland Chinese markets. My results suggest that overall both Shanghai and Shenzhen markets have established long-term equilibrium relations with other markets within the region. Our long-term causality results also show that the Chinese mainland markets are increasingly influenced by other markets. However, our results also suggest that investors could still benefit from investing in mainland Chinese equity markets. Compared with other more matured markets such as the Hong Kong and Singapore markets, the potential benefits of diversification from investing in mainland Chinese markets may still be quite large due to its relatively weak linkage with international markets.

\section{References}

Bekaert, G., and Harvey, C. R. 1995. Time-varying world market integration. Journal of Finance 50: 403-444.

Chan, B.,and Lo, W. 2000. Financial market integration in the greater China Bloc: Evidence from causality investigation of stock returns. Asia Pacific Journal of Finance 3: 53-69.

Elliott, G.; Rothenberg, T.; and Stock, J. 1996. Efficient tests for an autoregressive unit root, Econometrica 64: 813-836.

Giles, J. A., and Mirza, S. 1999. Some pretesting issues on testing for granger noncausality. Econometrics Working Paper EWP9914, University of Victoria.

Groenewold, N., and Tang, S. H. K., Wu, Y. 2004. The dynamic interrelationships between the greater China share markets. China Economic 
Review 14: 45-62.

Hacker R. S., and Hatemi-J, A., 2000. The size properties of Toda and Yamamoto test statistics for causality using asymptotic and bootstrap distributions, working paper.

Hatemi-J, A., and Roca, E. 2004. An examination of the equity market price linkage between Australia and the European Union leverage bootstrap method. The European Journal of Finance 1-14.

Huang, B.-N., and Yang, C. W. 2000. Financial markets integration and segmentation under regional economic blocs: A dynamic conditional correlation approach. Advances in Pacific Basin Business, Economics, and Finance 4: 233-50.

Huang, B.-N.; Yang, C. W.; and Hu, J. W. 2000. Causality and cointegration of stock markets among the United States, Japan and the South China Growth Triangle. International Review of Financial Analysis 9: 281-297.

Johansen, S. 1988. Statistical analysis of cointegration vectors. Journal of Economic Dynamics and Control 12: 231-54.

Kim, Y., and Shin, J. 2000. Interactions among China-related stocks. Asia-Pacific Financial Markets 7: 97-115.

Laurence, M.; Cai, F.; and Qian, S. 1997. Weak-form efficiency and causality tests in Chinese stock markets. Multinational Finance Journal 1: 291-307.

Lo, W. C., and Chan, W. S. 2000. Diagnosing shocks in stock market returns of Greater China. Multinational Finance Journal 4: 269-88.

Osterwald-Lenum, M. 1992. A note with quantiles of the asymptotic distribution of the maximun likelihood cointegration rank test statistics: Four cases. Oxford Bulletin of Economics and Statistics 54: 461-72.

Poon, W. P. H., and Fung, H. G. 2000. Red chips or H shares: with China-backed securities process information the fastest? Journal of Multinational Financial Management 10: 315-343.

Rambaldi, A. N., and Doran, H. E. 1996. Testing for Granger non-causality in cointegrated systems made easy. Working Papers in Econometrics and Applied Statistics, Department of Econometrics, The University of New England: 22 pages.

Shanghai Daily, Chinese daily newspaper, published in Shanghai China.

Sjoo, B. and Zhang, J. 2000. Market segmentation and information diffusion in China's stock markets. Journal of Multinational Financial Management 10: 421-438.

Toda, H. Y., and Yamamoto, T. 1995. Statistical inference in vector autoregressions with possibly integrated processes. Journal of Econometrics. 66: 225-50.

Zapata, H. O., and Rambaldi, A. N. 1997. Monte Carlo evidence on cointegration and causation. Oxford Bulletin of Economics and Statistics 59: 285-98.

Zivot, E., and Andrew, D. W. K. 1992. Further evidence on the great crash, the oil-price shock, and the unit-root hypothesis. Journal of Business \& Economic Statistics 10: 251-270. 